Delayed return of spontaneous circulation (the Lazarus phenomenon) after cessation of out-of-hospital cardiopulmonary resuscitation

Kuisma, Markku

2017-09

Kuisma , M , Salo , A , Puolakka , J , Nurmi , J , Kirves , H , Vayrynen , T \& Boyd , J 2017 , '

Delayed return of spontaneous circulation (the Lazarus phenomenon) after cessation of

out-of-hospital cardiopulmonary resuscitation ' , Resuscitation , vol. 118 , pp. 107-111 . https://doi.org/10.1016/j.resus

http://hdl.handle.net/10138/297928

https://doi.org/10.1016/j.resuscitation.2017.07.022

publishedVersion

Downloaded from Helda, University of Helsinki institutional repository.

This is an electronic reprint of the original article.

This reprint may differ from the original in pagination and typographic detail.

Please cite the original version. 


\title{
Delayed return of spontaneous circulation (the Lazarus phenomenon) after cessation of out-of-hospital cardiopulmonary resuscitation ${ }^{\text {th }}$
}

\author{
Markku Kuisma ${ }^{a, *}$, Ari Salo ${ }^{a}$, Jyrki Puolakka ${ }^{a}$, Jouni Nurmi ${ }^{a}$, Hetti Kirves ${ }^{c}$, \\ Taneli Väyrynen ${ }^{\mathrm{b}}$, James Boyd ${ }^{\mathrm{a}}$ \\ a Department of Emergency Medicine, Section of Emergency Medical Services, Helsinki University Hospital, Helsinki, Finland \\ b Emergency Medical Services, Vaasa Central Hospital, Vaasa, Finland \\ ${ }^{\mathrm{c}}$ Emergency Medical Services, Hospital District of Helsinki and Uusimaa, Hyvinkää, Finland
}

\section{A R T I C L E I N F O}

\section{Article history:}

Received 15 May 2017

Received in revised form 13 July 2017

Accepted 21 July 2017

\section{Keywords:}

Cardiopulmonary resuscitation

Death

Lazarus phenomenon

\begin{abstract}
A B S T R A C T
Introduction: The delayed return of spontaneous circulation (ROSC) after cessation of cardiopulmonary resuscitation (CPR), also known as the Lazarus phenomenon, is a rare event described in several case reports. This study aims to determine the incidence and the time of occurrence of the Lazarus phenomenon after cessation of out-of-hospital CPR.

Methods: This prospective observational cohort study was conducted in the Helsinki Emergency Medical Service in Finland from 1 January 2011 through 31 December 2016. All out-of-hospital CPR attempts were carefully monitored for $10 \mathrm{~min}$ after the cessation of CPR in order to detect delayed ROSC.

Results: Altogether, 2102 out-of-hospital cardiac arrests occurred during the six-year study period. CPR was attempted in 1376 (65.5\%) cases. In 840 cases (61.0\% of all attempts) CPR attempts were terminated on site. The Lazarus phenomenon occurred five times, with an incidence of 5.95/1000 (95\% CI 2.10-14.30) in field-terminated CPR attempts. Time to delayed ROSC from the cessation of CPR varied from 3 to 8 min. Three of the five patients with delayed ROSC died at the scene within 2-15 min while two died later in hospital within 1.5 and $26 \mathrm{~h}$, respectively.

Conclusions: We observed that the Lazarus phenomenon is a real albeit rare event and can occur a few minutes after the cessation of out-of-hospital CPR. We suggest a 10-min monitoring period before diagnosing death. CPR guidelines should be updated to include information of the Lazarus phenomenon and appropriate monitoring for it.
\end{abstract}

(c) 2017 Elsevier B.V. All rights reserved.

\section{Introduction}

The delayed return of spontaneous circulation (ROSC) after the cessation of cardiopulmonary resuscitation (CPR) is also called the Lazarus phenomenon or autoresuscitation. It was first reported in 1982 [1] and, thereafter, numerous case reports and three surveys have been published [2-8]. However, no prospective studies of the Lazarus phenomenon have been conducted and, hence, its true incidence remains unknown. Similarly, the exact time to delayed ROSC is not known since signs of life may not have been monitored continuously after the cessation of CPR.

\footnotetext{
A Spanish translated version of the abstract of this article appears as Appendixi $\mathrm{n}$ the final online version at http://dx.doi.org/10.1016/j.resuscitation.2017.07.022.

* Corresponding author.

E-mail address: markku.kuisma@hus.fi (M. Kuisma).
}

Recommendations for how long monitoring should continue after stopping CPR are heterogeneous [3,9] or completely lacking. Current European Resuscitation Council (ERC) guidelines do not include any recommendation regarding whether patients should be monitored, or for how long, following unsuccessful CPR before declaring them dead [10].

This study aimed to determine the incidence and the time of occurrence of the Lazarus phenomenon after the cessation of outof-hospital CPR.

\section{Methods \\ Study setting and type}

This prospective observational cohort study was conducted in the Helsinki Emergency Medical Service (EMS) in Finland from 1 January 2011 through 31 December 2016. EMS uniformly serves the entire capital city of Helsinki, with a population of 615700 . The 
Department of Surgery at the Helsinki University Hospital approved the study plan. No informed consent was required from patients or their representatives due to the nature of the study.

\section{EMS}

The EMS system is three-tiered consisting of emergency medical technician-manned basic life support (BLS) ambulances, paramedic-manned advanced life support (ALS) ambulances, and a physician-manned unit. Fire engines used as first-response units are classified as BLS and the senior paramedic-manned medical supervisor unit serves as ALS. Cardiac arrest calls are attended by at least two units-that is, the nearest ambulance and a physicianmanned unit (medical supervisor unit if a physician unit is not available). A first-responding fire engine is dispatched if it is likely to reach the patient first.

\section{$C P R$}

CPR adhered to the 2010 and 2015 ERC guidelines [10,11]. During the study period, no devices for mechanical chest compression were used. All patients received closed-chest CPR, that is, emergency thoracotomies were not performed. Following unsuccessful CPR, patients were pronounced dead on scene except for a few cases of accidental hypothermia which were transported under continuous CPR allowing them to receive invasive warming in the hospital operating theatre.

CPR by EMS was recommended to continue for up to $35 \mathrm{~min}$ accompanying ventricular fibrillation and up to $20 \mathrm{~min}$ accompanying asystole and pulseless electrical activity (PEA) The EMS order of when not to initiate CPR has been described elsewhere [12]. This do-not-attempt-resuscitation (DNAR) order was revised in November 2015 to better address traumatic cardiac arrests and to simplify decision-making during asystole and PEA. In case of the initial rhythms of asystole and PEA, the maximum time to the initiation of ALS was removed from the DNAR order leaving the time to initiate CPR the only point allowing for a decision to be taken. Case-by-case decision-making was added to the order to account for EMS-witnessed traumatic cardiac arrests or traumatic cardiac arrests with a short ambulance response time.

\section{Monitoring after cessation of CPR}

In Helsinki routine EMS monitoring after the cessation of CPR was introduced in 2010 following a malpractice case in another part of Finland that gained much media attention. All out-ofhospital CPR attempts were carefully monitored for $10 \mathrm{~min}$ after the cessation of CPR in order to detect delayed ROSC of any duration. The Lazarus phenomenon was defined as delayed ROSC after the cessation of CPR. Post-CPR monitoring followed cases when the patient was intubated, alternative airway devices were used, adrenaline (or any other intravenous medication) was administered, the patient was defibrillated, or received prolonged ( $>10 \mathrm{~min}$ ) basic CPR, that is, chest compressions and bag-mask ventilation. Monitoring included ECG, capnography, and visual observation of the patient to detect signs of life such as breathing, swallowing, or movement. Cardiac ultrasound (US) was used when appropriate by the physician-manned unit. A ventilation bag or ventilator was ordered disconnected from the intubation tube at the beginning of the monitoring period in order to prevent the development of auto-PEEP (positive end-expiratory pressure). Following a 10-min monitoring period, patients were declared dead if no signs of life were detected.

\section{Data collection and analysis}

EMS has had an Utstein style-based cardiac arrest registry since $1994[13,14]$. All out-of-hospital cardiac arrests are prospectively entered into the registry. If a Lazarus phenomenon occurred, the on-duty physician or the medical supervisor completed a separate Lazarus study form in addition to a standard cardiac arrest data form. In addition to the structured data, the Lazarus study form included a section where the entire CPR process was described in chronological order. The physician responsible for the cardiac arrest registry validated data on a case-by-case basis. Electronic patient reports from EMS (Merlot Medi ${ }^{\circledR}$, CGI, Finland), hospital patient records, and autopsy reports were retrieved.

For normally distributed continuous variables, the mean and standard deviation (SD) were presented. The median and interquartile range (IQR) were presented for non-normally distributed data. We calculated the 95\% confidence interval (CI) for the incidence of the Lazarus phenomenon. Statistical testing was neither planned nor performed due to the small number of cases with delayed ROSC.

\section{Results}

During the six-year study period a total of 2102 out-of-hospital cardiac arrests occurred in Helsinki. CPR was attempted in 1376 (65.5\%) cases. In 840 cases (61.0\% of all attempts), CPR attempts were terminated on scene.

\section{Incidence and time of occurrence}

The Lazarus phenomenon occurred five times, with an incidence of 5.95/1000 (95\% CI 2.10-14.30) in field-terminated CPR attempts and 2.38/1000 (95\% CI 0.80-5.70) among all out-of-hospital cardiac arrests. Time to delayed ROSC from the cessation of CPR varied from 3 to $8 \mathrm{~min}$ ( $3 \mathrm{~min}$ in three cases, $6 \mathrm{~min}$ in one case, and $8 \mathrm{~min}$ in one case).

\section{Case features}

None of the five Lazarus cases presented as classic sudden outof-hospital cardiac arrest with strictly guideline-based CPR. Two patients (cases 1 and 4) were permanent nursing home residents of an advanced age. One patient (case 2 ) suffered massive external bleeding and, therefore, fluid resuscitation was a priority over adrenaline administration during CPR. In case 4, major bleeding from the lungs or the trachea to the intubation tube predisposed the patient to auto-PEEP. Four of the five cases presented with PEA both as an initial rhythm and as the rhythm recorded when CPR was stopped.

Although cardiac US was not routine during every CPR attempt it was used in three of four cases to confirm no mechanical cardiac activity was present when CPR was stopped accompanying PEA.

There were two protocol deviations. In case 2, the ventilation bag was not immediately disconnected from the intubation tube when CPR ceased. In addition, in case 5, a noradrenaline infusion initiated before cardiac arrest was not discontinued when CPR stopped.

Detailed descriptions of the five Lazarus cases are presented in Tables 1 and 2 .

\section{Outcome}

All five patients remained deeply comatose after delayed ROSC. In two patients, prehospital advanced life support was continued (cases 2 and 3). In three cases, patients were allowed to breathe spontaneously and were only observed due to the dismal situation. 
Table 1

Detailed description of the five Lazarus cases: data until the cessation of CPR.

\begin{tabular}{|c|c|c|c|c|c|c|c|c|c|c|c|}
\hline & Age (years) & Sex & $\begin{array}{l}\text { Cause of cardiac } \\
\text { arrest }\end{array}$ & Initial rhythm & Witness status & $\begin{array}{l}\text { Adrenaline } \\
\text { (mg) }\end{array}$ & Shocks (n) & Airway & $\begin{array}{l}\text { Duration of } \\
\text { CPR (min) }\end{array}$ & $\begin{array}{l}\text { Rhythm when } \\
\text { CPR stopped }\end{array}$ & $\begin{array}{l}\text { US confirmation of } \\
\text { non-beating heart } \\
\text { when CPR stopped }\end{array}$ \\
\hline Case 1 & 97 & $\mathrm{~F}$ & Unknown ${ }^{\mathrm{a}}$ & Asystole & Bystander & 0 & 0 & $\begin{array}{l}\text { Pharyngeal } \\
\text { tube }\end{array}$ & 16 & Asystole & No \\
\hline Case 2 & 30 & $\mathrm{~F}$ & Haemorrhage & PEA & EMS witnessed & 3 & 0 & Intubation & 31 & PEA & Yes \\
\hline Case 3 & 63 & $\mathrm{M}$ & $\begin{array}{l}\text { Carbon monoxide } \\
\text { poisoning }\end{array}$ & PEA & Unwitnessed & 2 & 1 & Intubation & 12 & PEA & Yes \\
\hline Case 4 & 91 & $\mathrm{~F}$ & Unknown ${ }^{\mathrm{a}}$ & PEA & Bystander & 0 & 0 & Intubation & 16 & PEA & No \\
\hline Case 5 & 61 & $\mathrm{~F}$ & Aortic dissection & PEA & EMS witnessed & 3 & 0 & Intubation & 18 & PEA & Yes \\
\hline
\end{tabular}

Abbreviations: $\mathrm{CPR}=$ cardiopulmonary resuscitation, $\mathrm{US}=$ ultrasound, $\mathrm{PEA}=$ pulseless electrical activity.

a Autopsy was not performed due to permanent nursing home status of the patient.

Table 2

Detailed description of the five Lazarus cases: data at and after auto ROSC.

\begin{tabular}{|c|c|c|c|c|c|c|c|c|c|c|c|}
\hline & $\begin{array}{l}\text { Time to auto } \\
\text { ROSC }(\min )^{\mathrm{a}}\end{array}$ & $\begin{array}{l}\text { Rhythm after } \\
\text { auto ROSC }\end{array}$ & $\begin{array}{l}\text { Detection of auto } \\
\text { ROSC }\end{array}$ & $\begin{array}{l}\text { Time from last } \\
\text { adrenaline } \\
\text { (min) }\end{array}$ & $\begin{array}{l}\text { First heart } \\
\text { rate (/min) }\end{array}$ & $B P^{\mathrm{b}(m m H g)}$ & $\mathrm{GCS}^{\mathrm{b}}$ & $\operatorname{Temp}\left({ }^{\circ} \mathrm{C}\right)$ & $\begin{array}{l}\text { Survived to } \\
\text { hospital }\end{array}$ & $\begin{array}{l}\text { Duration of } \\
\text { auto ROSC }\end{array}$ & Remarks \\
\hline Case 1 & 3 & Junctional & Agonal breathing + carotid pulse & & 37 & na & 3 & na & No & $2 \mathrm{~min}$ & \\
\hline Case 2 & 6 & Sinus & Swallowing + blood pressure & 15 & 30 & $120 / 50$ & 3 & 32.7 & Yes & $1 \mathrm{~h} 28 \mathrm{~min}$ & $\begin{array}{l}\text { Ventilation bag not } \\
\text { disconnected from } \\
\text { intubation tube }\end{array}$ \\
\hline Case 3 & 3 & Junctional & Breathing + carotid pulse + capnography & 7 & 118 & $170 / 80$ & 3 & 36.5 & Yes & $26 \mathrm{~h} 20 \mathrm{~min}$ & \\
\hline Case 4 & 3 & Sinus & Breathing + carotid pulse & . & 45 & na & 3 & na & No & $15 \mathrm{~min}$ & $\begin{array}{l}\text { Haemorrhagia from } \\
\text { intubation tube }\end{array}$ \\
\hline Case 5 & 8 & Slow ventricular rhythm & Breathing + movement & 14 & 40 & na & 3 & 35.7 & No & $3 \min$ & $\begin{array}{l}\text { Noradrenaline infusion } \\
(0.02 \mathrm{mg} / \mathrm{ml} \text { given } \\
50 \mathrm{ml} / \mathrm{h}) \text { not stopped }\end{array}$ \\
\hline
\end{tabular}

Abbreviations: $\mathrm{ROSC}=$ return of spontaneus circulation, $\mathrm{BP}=$ blood pressure, $\mathrm{GCS}=$ Glasgow Coma Score, $\mathrm{Temp}=$ tympanic temperature

a Calculated from the cessation of CPR.

${ }^{\mathrm{b}}$ Highest recorded prehospital value. 
Three of the patients with delayed ROSC died at the scene within 2-15 min, while two died later at hospital within 1.5 and $26 \mathrm{~h}$.

\section{Discussion}

\section{Principal findings}

We showed in a prospective study that delayed ROSC after cessation of out-of-hospital CPR is a real phenomenon that can occur in every EMS system. In our EMS system, the incidence of the Lazarus phenomenon was 6/1000 in field-terminated CPR attempts, an incidence higher than we expected based on the literature. However, this phenomenon is believed to be highly underreported both in the clinical setting and in the literature [8]. Careful monitoring played a crucial role in its detection since the delayed return of ROSC was of a very short duration (2-3 min) in two cases and, hence, might have gone unnoticed without continuous monitoring. The time to auto ROSC after the cessation of CPR varied between 3 and $8 \mathrm{~min}$. This finding supports the minimum monitoring time of $10 \mathrm{~min}$ before declaring a patient dead. In most cases, the heart rhythm was PEA both as an initial rhythm and when CPR ceased.

\section{Relation of results to other studies}

Previous literature consists of case reports, surveys, and some reviews. Based solely on case reports, the Lazarus phenomenon appears to be exceptionally rare, although surveys suggest that it may be much more common than believed and highly underreported. Case reports cover a wide range of patients (age, previous medical history, aetiology of cardiac arrest) and settings (prehospital, emergency department, intensive care unit), indicating that the Lazarus phenomenon is not confined to a specific patient type or clinical setting [2-5,7]. We should also note that these reports do not indicate that any decision to halt a resuscitation attempt is or was incorrect.

In France, 103 prehospital emergency care physicians completed a survey related to the Lazarus phenomenon in 2013 [15]. The existence of autoresuscitation was known by $69 \%$ of respondents. Almost half (45\%) of the physicians indicated that they had already witnessed autoresuscitation. The authors emphasized the need to address the Lazarus phenomenon during medical education. In a separate study among Dutch intensive care physicians, $37 \%$ of 311 respondents reported having witnessed autoresuscitation either after unsuccessful CPR or the withdrawal of care [16].

The physiological mechanisms behind the Lazarus phenomenon remain unknown. Several mechanisms have been proposed, including pulmonary hyperinflation or auto-PEEP, myocardial reperfusion, myocardial stunning, alkalosis, and a delayed action of the drugs used during CPR $[6,8]$. Auto-PEEP stands as perhaps the most discussed mechanism. If a patient is ventilated rapidly during CPR without time for exhalation, dynamic hyperinflation of the lungs occurs. The resulting auto-PEEP may prevent achieving ROSC. After auto-PEEP is relieved, spontaneous circulation may occur. In our material, predisposing factors (haemorrhage from the lungs and failure to disconnect the ventilation bag from the intubation tube) for auto-PEEP occurred in two cases.

\section{Relevance of the study results}

The results from this study have direct implications on CPR guidelines, educational programmes, and clinical practices in both prehospital and in-hospital settings. We recommend that a description of the Lazarus phenomenon and the importance of appropriate monitoring after the cessation of CPR should be included in international and national CPR guidelines. Although the incidence of the
Lazarus phenomenon remains exceptionally low, the possible consequences of an unrecognised case could be devastating, resulting in malpractice claims, negative media coverage, and psychological trauma to personnel and the relatives of the patient.

In our material, we found no pseudo-Lazarus cases, that is, patients who would had been falsely declared dead when in fact minimal life functions remained and went undetected after CPR ceased. In such cases, some level of circulation occurred throughout, although patients may have been clinically evaluated as being in PEA. Some of these cases may have been inadvertently reported as the Lazarus phenomenon in the literature. Regardless, both the Lazarus and pseudo-Lazarus phenomena emphasize the proper detection of the absence of life functions, particularly circulation, when the heart rhythm is PEA. In such cases, cardiac US, when available, should be used to detect mechanical cardiac activity. In this study, US was used in three of four cases when the rhythm was PEA after CPR was halted.

\section{Limitations and future studies}

The Lazarus phenomenon is a rare event. Therefore, this study is limited by the small number of cases of the delayed return of spontaneous circulation. However, a six-year study period is sufficiently long enough to determine the incidence in an EMS system of this call volume, particularly since all unsuccessful CPR attempts (excluding accidental hypothermia) were terminated in the field. Some cases might have been missed or remained unreported. However, the long history of reporting all cardiac arrests in the Utstein-based registry and the related quality assurance measures likely minimised underreporting. The incidence rate may not be directly transferable to other EMS systems since the incidence was likely affected by the presence of advanced directives. If the two permanent nursing home residents had a DNAR order they would not have been resuscitated and, hence, the incidence rate would have been lower. The protocol-based monitoring time was $10 \mathrm{~min}$, and, therefore, we cannot exclude the possibility that transient auto ROSC occurred after $10 \mathrm{~min}$ and remained undetected. In two cases with a delayed return of spontaneous circulation, standard operational procedures were not followed (delayed disconnection of the ventilation bag from the intubation tube and continued noradrenaline infusion). These two deviations may have contributed to the occurrence of auto ROSC. Future studies should focus on determining which patient or CPR-related factors predispose to the occurrence of auto ROSC and which patients either survive with a good outcome or might be suitable organ donors.

\section{Conclusions}

We determined that the Lazarus phenomenon is a real but rare event and can occur a few minutes after the cessation of outof-hospital CPR. We suggest a 10-min monitoring period before diagnosing death. As such, CPR guidelines should be updated to include information about the Lazarus phenomenon and appropriate monitoring for it.

\section{Funding}

This study was funded by the Hospital District of Helsinki and Uusimaa, Helsinki, Finland (research project number TYH2014221).

\section{Conflict of interest statement}

There are no financial or personal relationships with other people or organisations that could influence this paper. 


\section{Acknowledgements}

The authors are most thankful for all on-duty physicians and medical supervisors for their valuable help in data collection.

\section{References}

[1]. Linko K, Honkavaara P, Salmenperä M. Recovery after discontinued cardiopulmonary resuscitation. Lancet 1982;1:106-7.

[2]. Walker A, McClelland H, Brenchley J. The Lazarus phenomenon following recreational drug use. Emerg Med J 2001;18:74-5.

[3]. Kämäräinen A, Virkkunen I, Holopainen L, Erkkilä E-P, Yli-Hankala A, Tenhunen J. Spontaneous defibrillation after cessation of resuscitation in out-of-hospital cardiac arrest: a case of Lazarus phenomenon. Resuscitation 2007;75:543-6.

[4]. Duff J, Joffe A, Sevcik W, deCaen A. Autoresuscitation after pediatric cardiac arrest - is hyperventilation a cause. Pediatr EmergCare 2011;27:208-9.

[5]. Hagmann H, Oelmann K, Stangl R, Michels G. Is increased positive end-expiratory pressure the culprit? auroresuscitation in a 44-year-old man after prolonged cardiopulmonary resuscitation: a case report. J Med Case Rep 2016;10:364.

[6]. Adhiyaman V, Adhiyaman S, Sundaram R. The Lazarus phenomenon. J R Soc Med 2007; $100: 552-7$

[7]. Hornby K, Hornby L, Shemie S. A systematic review of autoresuscitation after cardiac arrest. Crit Care Med 2010;38:1246-53.

[8]. Sahni V. The lazarus phenomenon. J R Soc Med 2016;7:1-6.

[9]. Academy of Royal Medical Colleges. A code of practice for the diagnosis and confirmation of death. Academy of Medical Royal Colleges; 2008.
[10]. European resuscitation council guidelines for resuscitation 2015. Resuscitation 2015;95:1-311

[11]. European resuscitation council guidelines for resuscitation 2010. Resuscitation 2010:81:1219-451.

[12]. Skrifvars MB, Väyrynen T, Kuisma M, Castren M, Parr MJ, Silfverstople J, et al. Comparison of Helsinki and European Resuscitation Council do not attempt to resuscitate guidelines, and a termination of resuscitation clinical prediction rule for out-of-hospital cardiac arrest patients found in asystole or pulseless electrical activity. Resuscitation 2010;81:679-84.

[13]. Kuisma M, Määttä T. Out-of-hospital cardiac arrests in Helsinki: utstein style reporting. Heart 1996;6:18-23.

[14]. Perkins G, Jacobs I, Nadkarni V, Berg R, et al. Cardiac arrest and cardiopulmonary resuscitation outcome reports: update of the utstein resuscitation registry templates for out-of-hospital cardiac arrest a statement for healthcare professionals from a Task Force of the International Liaison Committee on Resuscitation (American Heart Association, European Resuscitation Council, Australian and New Zealand Council on Resuscitation, Heart and Stroke Foundation of Canada, Inter American Heart Foundation, Resuscitation Council of Southern Africa, Resuscitation Council of Asia); and the America Heart Association Emergency Cardiovascular Care Committee and the Council on Cardiopulmonary, Critical Care, Perioperative and Resuscitation. Resuscitation 2015;96:328-40.

[15]. Gerard D, Vaux J, Boche T, Chollet-Xemard C, Marty J. Lazarus phenomenon: knowledge, attitude and practice. Resuscitation 2013;84:e153.

[16]. Wind J, van Mook WN, Dhanani S, van Heurn EW. Determination of death after circulatory arrest by intensive care physicians: a survey of current practice in the Netherlands. J Crit Care 2016;1:2-6. 